\title{
Capitalizing on One's Advantages: Role of Core Self-Evaluations
}

\author{
Timothy A. Judge and Charlice Hurst \\ University of Florida
}

\begin{abstract}
The authors examined (a) whether core self-evaluations in adolescence and young adulthood predict income at midlife and (b) whether people with positive core self-evaluations are more likely to capitalize on advantages resulting from family socioeconomic status and academic achievement, resulting in even higher levels of income at midcareer. The sample consisted of participants from the National Longitudinal Survey of Youth, a national probability sample that first surveyed participants in 1979. The authors found that core self-evaluations and family socioeconomic status and academic achievement predict income and that, furthermore, high core self-evaluations enhance the benefits derived from these factors. Overall, it appears that individuals with positive core self-evaluations are particularly adept at translating early advantages into later economic success.
\end{abstract}

Keywords: career success, core self-evaluations, capitalizing, income attainment

Many have argued that success is produced by perseverance in the face of hardship and initial failure (Seligman \& Csikszentmihalyi, 2000). Yet, little mentioned are those who seize upon and exploit advantages, whether earned through personal effort or bestowed by fortune. As Seligman and Csikszentmihalyi noted, social and behavioral scientists "have come to understand quite a bit about how people survive and endure under conditions of adversity ... [h]owever, psychologists know very little about how normal people flourish under more benign conditions" (p. 5). Certainly, in more developed nations like the United States, such benign conditions are common in the lives of many, yet we do not see uniform levels of success among people subject to those conditions. Thus, although the widespread focus on what enables people to cope with disadvantage is understandable given its potential to lessen the impact of social problems, it is also useful to examine why some people with certain opportunities and circumstances linked to success flourish whereas others with the same advantages do less well and, at times, even founder.

According to Langston (1994), just as individuals respond to negative events by coping, they may respond to positive events via an analogous process of "capitalization" through which they capture benefits beyond those conferred by the events themselves. In two studies of college students, Langston found that capitalization (operationalized as people's reactions to-what they did with-the event) on daily positive events explained incremental variance in positive affect and involvement even when the objective event was controlled. Building on Langston's work, a later series of studies among couples and college students found that the social sharing of positive events with others increased positive affect and life satisfaction beyond the effects of the events themselves (Gable, Impett, Reis, \& Asher, 2004). Furthermore, these researchers

Timothy A. Judge and Charlice Hurst, Department of Management, Warrington College of Business, University of Florida.

Correspondence concerning this article should be addressed to Timothy A. Judge, Department of Management, University of Florida, Gainesville, FL 32611-7165. E-mail: tjudge@ufl.edu found that sharing positive news enhanced accessibility of the event in memory, partially mediating between sharing and wellbeing.

The findings from these studies on capitalization suggest that people can derive benefit not only from the tangible outcomes of advantageous circumstances but also by responding in certain ways to those circumstances. Other research suggests, in addition, that self-concept plays an important role in defining individuals' responses to beneficial experiences and, as a result, the rewards they reap (Brown \& McGill, 1989; Bryant, 2003; Wood, Heimpel, Newby-Clark, \& Ross, 2005). Although these studies have looked only at the very short-term effects of capitalization, they do suggest that long-term differences in success may be due to chronic or habitual tendencies to capitalize on fortuitous early life circumstances.

We sought to build on emergent research into capitalization and the role of self-concept. We examined whether positive core selfevaluations (CSEs) in adolescence and young adulthood enhance the impact of high academic achievement and family socioeconomic characteristics on income later in the career. Whereas previous literature has tended to focus on responses to relatively minor, everyday events and their short-term affective and health outcomes, in this study we focused on how positive self-concept may lead individuals to draw greater long-term material rewards from those aspects of youthful privilege and attainment that are typically associated with career success (i.e., socioeconomic status, education, etc.). Furthermore, in this article, we extend the nomological network of CSE by examining its main effects on income when individuals are at the peak of their careers, as well as its interactive effects with youthful circumstances and achievements. In the next section of the article, we provide a brief overview of CSEs, and then we develop hypotheses regarding the main and interactive effects of CSE on income attainment.

\section{Overview of CSEs}

Introduced by Judge, Locke, and Durham (1997) as a dispositional basis of job and life satisfaction, CSE is defined as "funda- 
mental premises that individuals hold about themselves and their functioning in the world" (Judge, Erez, \& Bono, 1998, p. 168). CSE is indicated by four lower order personality traits (selfesteem, generalized self-efficacy, emotional stability, and locus of control) that have been widely studied separately but rarely studied in concert, despite their high intercorrelations and poor discriminant validity, as evidenced by similar patterns of relationships with outcomes such as subjective well-being (Judge, Erez, Thoresen, \& Bono, 2002), job satisfaction (Judge \& Bono, 2001), and job performance (Erez \& Judge, 2001). There is considerable evidence that the CSE traits are reflections of a more basic orientation toward oneself and one's approach toward one's environment. Erez and Judge and Judge, Erez, Bono, and Thoresen (2003) have found support for the hypothesis that the higher order core concept explains the substantial associations among the individual traits. Furthermore, in the Erez and Judge study, the unique portions of the four component traits failed to explain incremental variance in any of the criteria (e.g., productivity, motivation, job satisfaction, task performance) beyond the CSE factor. Thus, as Judge and colleagues have argued, CSE may help to integrate the study of several interrelated aspects of self-concept as well as provide a parsimonious, yet valid, method of predicting work-related outcomes from personality.

\section{Hypotheses}

\section{Main Effects of CSE on Income}

There is some research linking "positive" traits with income (Lyubomirsky, King, \& Diener, 2005; Ng, Eby, Sorensen, \& Feldman, 2005; Roberts, Caspi, \& Moffitt, 2003). Recently, in a meta-analysis of the determinants of career success, $\mathrm{Ng}$ et al. (2005) examined the relationships of salary with numerous broadly studied individual differences, finding positive correlations with the two CSE traits examined (locus of control and Neuroticism). Also, Lyubomirsky et al. (2005) conducted a review of research to examine whether happiness leads to success, including financial prosperity. They argued that positive emotions-and the traits associated with them (e.g., self-efficacy, confidence, optimism, etc.) - "lead people to think, feel, and act in ways that promote both resource building and involvement with approach goals" (p. 804). Based on dozens of research findings, they concluded that people high in positive traits tend to be more financially prosperous. However, only a few of the studies were longitudinal in nature. Those that were longitudinal covered a shorter period of time than the current study and examined the impact of constructs related to affective disposition, like cheerfulness (Diener, Nickerson, Lucas, \& Sandvik, 2002) and trait positive affect (Staw, Sutton, \& Pelled, 1994), rather than self-concept. Given findings that CSE predicts incremental variance beyond the Big Five and trait positive affect in job and life satisfaction (Heller, Judge, \& Watson, 2002; Judge et al., 2003) and performance (Judge et al., 2003), a more explicit consideration of self-concept may be useful in better understanding the dispositional basis of work outcomes.

Prior research suggests that CSE may exert main effects on income, interorganizationally (mobility across jobs and occupations) and intraorganizationally (activity within a job or occupation). First, it may influence the situations into which individuals select themselves. Headey and Wearing (1989) suggested that each individual has an equilibrium pattern of life events borne of stable individual differences. They found that Neuroticism, one of the core traits that indicate CSE, was associated with adverse financial and job events (i.e., financial crises, unemployment, coworker conflict) over a 7-year period. A similar study (Magnus, Diener, Fujita, \& Payot, 1993) found that individuals high in Neuroticism experienced more problematic life events, such as failure to get into graduate school, in the 4 years following initial personality measurement. Finally, high-CSE individuals tend to search more intensely for jobs during periods of unemployment (Wanberg, Glomb, Song, \& Sorenson, 2005) and to obtain more objectively complex jobs (Judge, Bono, \& Locke, 2000). Thus, CSE may influence the types of jobs and occupations people select, the stability of their employment, and their experiences at work, all of which might affect income.

CSE may also affect income via its effects intraorganizationally on motivation and performance. Erez and Judge (2001) found that university students with positive CSE had higher levels of task motivation (i.e., they persisted longer and reported more motivation to do well) and that motivation partially mediated between CSEs and task performance. In a separate sample of sales representatives, they found that CSE positively affected supervisorrated and sales performance and that goal-setting motivation partially mediated these relationships. Furthermore, in two longitudinal studies, Judge, Bono, Erez, and Locke (2005) found that individuals with positive CSE are more likely to select selfconcordant work goals, and are more likely to attain those goals, which should lead to greater work effectiveness.

In sum, it seems that people with high CSE are more committed to and persistent in pursuit of their goals and perform more competently in their jobs. These tendencies should, logically, lead to higher income over the life course:

Hypothesis 1: CSEs measured in young adulthood will be positively related to income at midlife.

\section{Income Effects of Adolescent and Young Adulthood Life Experiences}

Previous research on capitalization has appropriately focused on common, everyday events because the criterion was immediately experienced affect. In contrast, our focus is on a broad, cumulative criterion-income. Thus, we examined major aspects of adolescent and young adult experience that are known to affect individuals' career prospects. Specifically, we were interested in the moderating effect of CSE on the relationships of income attainment with advantages conferred by the family of origin (parental educational attainment and occupational prestige, childhood freedom from poverty) and advantages that an individual earns early in life (educational attainment, high school grade point average [GPA], and standardized test scores). These variables are all commonly used indicators of socioeconomic status that have been linked to income and other occupational outcomes in prior research (Chênevert \& Tremblay, 2002; Ek, Sovio, Remes, \& Jarvelin, 2005; Haveman \& Wolfe, 1995; Pfeffer, 1977; Smart \& Pascarella, 1986). For instance, Ek et al. found that prestige of the father's occupation and educational attainment by the mother during childhood predicted entrance into the labor market. Also, Chênevert and Tremblay found that the status of fathers' occupa- 
tions was positively related to their adult children's wages. Finally, although parental income seems to affect high school completion and entry into college more than it does later academic achievement (G. J. Duncan, Yeung, Brooks-Gunn, \& Smith, 1998), parental education influences entry into postgraduate education (Mullen, Goyette, \& Soares, 2003).

In general, family socioeconomic factors likely affect salary through their impact on career aspirations and decision making (Hartung, Porfeli, \& Vondracek, 2005), access to educational and social resources (Smart \& Pascarella, 1986), and educational attainment (G. J. Duncan et al., 1998; Mullen et al., 2003). Also, family socioeconomic status, particularly income, may be linked to tendencies to capitalize. MacLeod and Conway (2005) found that household income was positively related to tendencies to anticipate future positive experiences which, in turn, is related to savoring and reminiscing on positive experiences (Bryant, 2003).

As for variables related to advantages earned through effort, $\mathrm{Ng}$ et al. (2005) found a corrected correlation of .29 between salary and education level. Furthermore, positive relationships have been found in numerous studies between occupational attainment and both school performance (Ek et al., 2005; Margit, Vondracek, Capaldi, \& Porfeli, 2003) and standardized achievement tests that capture cognitive ability (Dreher \& Bretz, 1991; Margit et al., 2003; O'Reilly \& Chatman, 1994; Tsui, 1998). Thus, it seems clear that such factors are potential resources upon which individuals may capitalize in their pursuit of material success.

Given the wealth of prior findings, we expected that an individual's family socioeconomic background-what we call family advantages (parents' education and occupational prestige, freedom from poverty as a child) — and educational attainment, in the form of years of education, high school grades, and standardized test scores, will be positively related to income at midlife:

Hypothesis 2: Individuals' family advantages will be related to their income, such that individuals will earn more as a result of (a) parental education, (b) parental occupational prestige, and (c) freedom from family poverty status.

Hypothesis 3: Individuals' educational attainment will be related to their income, such that individuals will earn more as a result of (a) years of education, (b) high school GPA, and (c) standardized test (Scholastic Aptitude Test; SAT) scores.

\section{CSEs as a Moderator of the Effect of Early Advantage}

It is well-known that certain personality traits influence how effectively individuals cope with difficult life circumstances (e.g., Fredrickson, Tugade, Waugh, \& Larkin, 2003; Tugade \& Fredrickson, 2004). However, we focused in the present research on how people flourish under more benign and generalized circumstances. That is, we were interested in whether positive self-regard provides any added value not only in overcoming the "bad" but also in capitalizing on the "good."

High-CSE individuals may better utilize their resources for a number of reasons. First, CSE is expected to influence situational appraisals. As noted by Judge, Locke, Durham, and Kluger (1998), "People who consider themselves worthy and able to cope with life's exigencies bring a 'positive frame' to the events and situations they encounter" (p. 31). Thus, CSE may affect the extent to which one views a given circumstance as beneficial. For example, people with high CSE not only obtain jobs that are objectively more challenging but they also view their jobs as having more positive characteristics (Judge et al., 2000). Along similar lines, people high in positive affective traits tend to experience more gratitude, defined as the recognition of a positive outcome that may not necessarily be deserved or earned (McCullough, Tsang, \& Emmons, 2004). Thus, because of the way they tend to appraise situations, high-CSE individuals may reap more affective and behavioral benefits from beneficial life circumstances, even those for which they are not solely responsible.

In addition to appraising propitious circumstances more positively, high-CSE individuals may view these circumstances and the opportunities they afford as being consistent with their selfimage. As an illustration, Brown and McGill (1989) found that individuals with high self-esteem experienced health benefits (selfrated and objectively measured) from positive life events whereas those with low self-esteem actually suffered ill effects. Another study (Wood et al., 2005) found that individuals with low selfesteem experienced heightened anxiety after success whereas high self-esteem individuals experienced enhanced affect and positive self-relevant thoughts. Further analyses suggested that the reactions of individuals with low self-esteem to recent positive events may be driven by self-verification and self-protection motives. With regard to the former, people with low self-esteem tended to make statements contradicting their role in their success. As for the latter, success seemed to trigger more concerns for individuals with low self-esteem about how well they could do in the future.

The results of these studies are consistent with other research on self-verification theory, according to which individuals have such a strong need for coherence that they prefer confirmation of a negative self-concept over positive feedback that conflicts with their self-view (for a review, see Swann, 2005). In particular, Schroeder, Josephs, and Swann (2004) found that individuals with low self-esteem tended to remain in jobs in which there were no raises and to leave jobs with increasing wage levels, whereas the opposite was true among those with high self-esteem. Moreover, the effects of self-esteem on turnover based on pay emerged only after a period of 2 years, indicating the necessity of examining these processes over a lengthier period of time than is covered by most studies on capitalization.

A final basis for the moderating role of CSE, consistent with research cited above, is its effects on motivation and, ultimately, performance. Although having parents who hold prestigious positions or earning a college degree can be advantageous, it may be up to the individual to realize the benefits by grasping resultant opportunities and persisting until those opportunities bear fruit. A recent study by Bono and Colbert (2005) suggests some support for the idea that high-CSE individuals will do just that. They found that individuals with positive CSE were as strongly committed to goals for performance improvement when they had received feedback from others that was more positive than their self-ratings as when they had received less positive feedback from others. On the other hand, individuals with negative CSE were less committed to their goals when there was any discrepancy between ratings. Thus, it seems that high-CSE individuals not only reacted more constructively to negative feedback but were also motivated to increase their performance when they learned they were already doing well. 
In sum, CSE should intensify the beneficial effects of adolescent and young adulthood resources and achievements on income at midcareer because of its relationships with appraisals, motivation, and performance. Individuals with high CSE will view situations more positively, will see themselves as more worthy of the advantages conferred by those situations, and will work harder to extract the benefits. These tendencies should cause early advantages to cascade into further advantages and opportunities across the life span, leading to higher levels of occupational attainment and, as a result, income:

Hypothesis 4: CSE will moderate the effects of (a) family advantages (parental education, parental occupational prestige, and freedom from family poverty) and (b) educational attainment (years of education, high school GPA, and standardized test scores) on income such that the effects of these variables will be stronger for those high in CSE than for those low in CSE.

\section{Control Variables}

To ensure that our hypothesis tests were as valid as possible, we controlled for several variables that had the potential to affect our findings. In each of the regression equations, we controlled for race, gender, hours worked per year, and marital status. Recent meta-analytic research found that all of these factors are related to salary (Ng et al., 2005). Salaries tend to be higher among Whites, men, and individuals who are married. The number of hours worked increases income as well. Also, race and gender are associated with self-concept (Birndorf, Ryan, Auinger, \& Aten, 2005), academic performance, and educational attainment (Allen, 1992; Charles \& Luoh, 2003). Finally, because net household income was used as the outcome variable, spouse's income was included as a control in order to isolate each participant's contribution to household income.

\section{Method}

\section{Participants and Procedure}

Data were obtained from the National Longitudinal Survey of Youth (NLSY79), which is a nationally representative sample of 12,686 men and women who were 14 to 22 years old when they were first interviewed in 1979 (and thus were between 37 and 45 years old in 2002). The NLSY79 was initiated and is administered by the Bureau of Labor Statistics, a branch of the U.S. Department of Labor.

Participants in the NLSY79 were first interviewed in 1979 and were interviewed annually until 1994, at which time they were interviewed on a biennial basis. Naturally, because many of the participants have made transitions from school to work, and from their parents' homes to being parents and homeowners, sample attrition has occurred in the 24-year time frame over which the data used in this study were collected. However, apart from the roughly 3,000 participants who were dropped from the study in 1990 (because of budget constraints), the average attrition level was quite small, averaging roughly 200 to 300 individuals from one interview to the next. Overall, the 1979-2002 response rate for those who remained in the study (were neither dropped nor deceased) was $80.9 \%$. By 2002, 7,724 of the original participants remained in the study. Participants in the 2002 sample were $72 \%$ Caucasian, 50\% male, and 59\% married. The average participant had 13.19 years of education, worked an average of $35 \mathrm{hr}$ per week, and had an average annual income of $\$ 55,564$.

Participants were interviewed either in person in their dwellings or via telephone. Across the panels, $81.3 \%$ of the interviews were completed in person. At the local level, interviewers were responsible for contacting participants in their caseloads; for participants who could not be located or who initially refused cooperation, the case was transferred to the national field office for follow-up. In addition, at various points in the study, participants signed a release allowing access to school records. Participants were paid $\$ 10$ for each interview until 1996 when the amount was increased to $\$ 20$.

\section{Measures}

Demographic characteristics. Participants' race was noted by the interviewer in the 1980 survey and was coded as $1=$ White, $2=$ Black, $3=$ other, which we subsequently recoded into $1=$ White, $0=$ other. Participants' sex was coded by the interviewer in the 1982 survey and was coded $1=$ male, and $2=$ female, which we recoded into $0=$ female, $1=$ male. Participants' marital status was measured with a 2002 interview question asking the individuals whether they were never married, married, separated, divorced, or widowed. The variable was coded 1 if the participant was currently married and 0 if the individual was divorced, widowed, separated, or never married.

CSEs. In 2003, Judge et al. (2003) developed and validated a direct measure of CSEs. Obviously, this measure was not available in the NLSY79 database, so we relied on available items that closely corresponded to the 12-item Core Self-Evaluations Scale (CSES). The items are provided in the Appendix. Three items (Items 1, 2, and 3) were taken from Pearlin's personal mastery measure (Pearlin, Lieberman, Menaghan, \& Mullan, 1981), which assesses the degree to which individuals perceive themselves in control of forces that impact their lives. Five items (Items 4, 5, 6, 7, and 8) were taken from Rosenberg's (1989) self-esteem measure. Two items (Items 9 and 10) were taken from the Center for Epidemiological Studies Depression scale (see Radloff, 1997; Ross \& Mirowsky, 1989). Two items (Items 11 and 12) were taken from Rotter's (1966) internal-external locus of control measure. Each of these items was evaluated on a 1-4 Likert-type scale. The internal consistency reliability (coefficient alpha) of this scale was .80 .

To test the convergent validity of this scale, we administered it, along with the 12-item CSES and several other "filler" scales, to a sample of 602 undergraduates. The correlation between the two scales was .82. This level of convergent validity is comparable to that of established measures of other personality traits. For example, in studies that have examined its convergent validity (Gosling, Renfrow, \& Swann, 2003; John \& Srivastava, 1999; Lee, Ashton, \& de Vries, 2005; Woods \& Hampson, 2005), the Big Five Inventory (John \& Srivastava, 1999) measure of Neuroticism correlates $\bar{r}=.74$ with other measures of neuroticism. Thus, judging from the standards used to evaluate convergent validities in the personality literature (e.g., Cunningham, Preacher, \& Banaji, 2001; Hicklin \& Widiger, 2000; Stöber, 2001), it appears that the 
measure of CSEs used in this study displays appreciable convergent validity.

Parents' education. Parents' education was measured with interviewer questions asking the participant, "What is the highest grade or year of regular school that your mother ever completed?" The same question was asked with respect to the participant's father. For both questions, the number of years of education that the parent received (e.g., high school diploma $=12$ years, 4-year college degree $=16$ years) was recorded, with 21 years being the highest possible value. The correlation between years of education of the mother and the father was .66.

Parents' occupational prestige. In the 1979 survey, interviewers asked participants the occupation of their mother and father. Verbatim responses to the open-ended questions were then coded according to the three-digit 1970 Census classifications (U.S. Census Bureau, 1971). We converted these three-digit codes into occupational status ratings using the Duncan index of occupational prestige (O. D. Duncan, 1961). The resulting scores, on a 0-100 scale, may be interpreted as estimates of occupational prestige, where higher scores indicate more prestigious occupations. For example, a judge has a Duncan score of 93, whereas a farm laborer has a Duncan score of 7. As noted by Warren and Hauser (1997), occupational prestige or status of one's family of origin provides important information on an individual's class or status within a social hierarchy. Thus, Duncan scores were calculated as the mean of mother's and father's Duncan scores. If one parent did not work outside the household, the Duncan score for the parent who did work outside the home was used. The correlation between the Duncan score of the mother and the father was .10.

Family poverty status. Family poverty status at the time of the initiation of the study was coded using the 1978 Poverty Income Guidelines (U.S. Office of Economic Opportunity/Community Services Administration, 1978), updated yearly by the U.S. Department of Health and Human Services. Respondents were determined to be in poverty if their 1978 family income was below the Poverty Income Guidelines. The guidelines are localized (i.e., by state) and are adjusted by family size and by farm versus nonfarm families. The variable was coded as $0=$ not in poverty, $1=$ in poverty.

Participant years of education. Participants' education level was measured by an interviewer question: "What is the highest grade of regular school that you have completed and gotten credit for?" Interviewers recorded answers in terms of number of years, where $12=$ high school diploma and $16=4$-year college degree, up to a maximum of 21 years.

High-school GPA. Transcript records were obtained on participants by NLS researchers through contacting participants' high schools and obtaining their records under a written release by participants (see Rumberger \& Daymont, 1982). Final course grades were coded for the available courses. Here, we averaged grades across up to 32 courses. Grades were scored in the typical fashion, where $4=\mathrm{A}, 3=\mathrm{B}, 2=\mathrm{C}, 1=\mathrm{D}$, and $0=\mathrm{F}$. Participants' GPA was calculated for all the courses for which grades were available.

SAT scores. SAT scores, for those who took the test and signed a release form, were obtained from high school transcripts. Test scores were available for 948 individuals. The math and verbal scores were added to form an SAT composite. Consistent with past research, where correlations between the two compo- nents have tended to be in the "high sixties" (Casey, Nuttall, \& Pezaris, 1995, p. 699), the two components were correlated ( $r=$ .75), albeit at a somewhat higher level than in some past research (e.g., Cullen, Hardison, \& Sackett, 2004).

Hours worked 1994-2002. In each interview, participants were asked to report how many hours they had worked in the past year. The hours reported were averaged from 1994 to 2002. The average participant worked an average of $1,757 \mathrm{hr}$ annually from 1994 to 2002, which translates into roughly $35 \mathrm{hr}$ per week (assuming 2 weeks' vacation time per year).

Spouse's income. To control for the spouse's contribution to household income, so that the results reflected the participant's unique contribution to their household income, we controlled for spouse's income contributed 1994-2002. If the participant was not married at the time, spousal income was coded as 0. If the participant's spouse did not work outside the home, this variable also was coded as 0 for that year.

Annual income 1994-2002. In each interview, participants were asked to report their total net household income in the past year. Income was averaged from 1994 to 2002. The Consumer Price Index was used to translate earlier salaries into 2002 dollars. Income, as well as several other study variables, was positively skewed. Although in many cases this skew is reduced through data transformations such as taking the natural $\log$ of salary (e.g., Finkelstein \& Boyd, 1998), such transformations change the meaning of the distribution of the variable, replacing a linear relationship with a nonlinear one. Often the theoretical rationale behind this presumed nonlinear relationship is not explicated (Russell \& Dean, 2000). As Gullikson (2006) noted, "Taking the natural log of the independent variable, for example, implies a 'diminishing returns' relationship." In terms of the hypothesized influences investigated here-most notably, the interactions involving CSEs-this would imply that the interactive effects would decline with increasing levels of income. Because we do not necessarily believe that this complex form of the relationship will hold, we did not transform the variables. Moreover, Busemeyer and Jones (1983) and Russell and Dean (2000, p. 168) have cautioned against the conventional use of such transformations on statistical grounds. Russell and Dean wrote, "Nonlinear transformations can cause more uncertainty in interpreting tests of moderation than they resolve" (p. 168). One of the statistical difficulties created by log transformations is Type II error. Russell and Dean noted that log transformations of positively skewed dependent variables (which is exactly the case here) "greatly enhance" the probability of committing a Type II error (concluding that an effect is nonsignificant when, in fact, it is significant).

Educational attainment and family advantages composite variables. Because the family advantages variables (parents' education, parents' occupational prestige, freedom from poverty status as a child) could be combined to form an overall index of familial advantage, we standardized them and combined them to form a single index. Similarly, we standardized the educational attainment variables (years of education, high school GPA, SAT score) and formed another single composite index. These variables are manifest or aggregate variables because (a) the items define or compose the concepts (e.g., educational attainment is defined by years of education and educational achievement) and (b) the items are not interchangeable indicators (each is a conceptually distinct variable). Because "internal consistency reliability is not an ap- 
propriate standard for evaluating the adequacy of the measures in formative models" (MacKenzie, Podsakoff, \& Jarvis, 2005, p. 712), we do not report coefficient alpha reliability estimates for these composite variables.

\section{Results}

Descriptive statistics and intercorrelations between the study variables are provided in Table 1 . In order to estimate the moderating effect of CSE on the relationship between the background variables and income, we estimated a series of multiple regressions, one for each hypothesized interaction. For the sake of parsimony, in the main regression analyses we report results only for the family advantages and educational attainment composite variables, but we should note that the significance level was the same for the individual components (parents' education, parents' occupational prestige, freedom from poverty status as a child, years of education, high school GPA, SAT score).

Consistent with Aiken and West (1991), in computing the interaction, we centered both CSEs and the background variables at their means. In the regressions, because practical effect-size estimates (Grissomand \& Kim, 2005; Kline, 2004) are available here, we report both raw or unstandardized $(B)$ coefficient estimates in their natural (dollar) units, as well as standardized regression $(\beta)$ coefficients. The unstandardized estimates can be interpreted as follows: A unit change in the independent variable produces a predicted change in income that is equal to the regression weight. For example, if the coefficient on hours worked per year is $\$ 10$, then for every hour a participant works, predicted income increases by $\$ 10$. For dichotomous independent variables, the interpretation is similar. For example, if the coefficient on marital status is $\$ 4,000$, all else equal, married individuals are predicted to earn $\$ 4,000$ more than nonmarried individuals. We conducted the regression analyses hierarchically, such that the control variables were entered on Step 1, the main effects (CSEs and the family advantages or educational attainment variable) were entered on Step 2, and the interaction was entered on Step 3. We report changes in variance explained $\left(\Delta R^{2}\right)$ at Steps 2 and 3, though the unstandardized and standardized coefficient estimates are reported for all variables based on the fully specified regression.

The regression results estimating the interactive effect of CSEs and family advantages (the composite of parents' education, parents' occupational prestige, and freedom from poverty) in predicting income are provided in Table 2. As the table shows, family advantages, CSEs, and the interaction predicted income; all of these effects were in the predicted direction. Table 3 presents the regression results involving CSEs and participants' educational attainment (years of education, high school grades, and SAT scores). As with family advantages, both the main effects (CSEs, participants' educational attainment) and the interaction were significant and in the predicted directions.

We should note that controlling for both advantages-family advantages and educational attainment - had very little effect on the interactions. In the analysis of family advantages, the interaction term changed little, increasing somewhat for the raw coefficient $(B=\$ 13,362, p<.01)$, and decreasing slightly for the standardized coefficient $(\beta=.109, p<.01)$. In the analysis of educational attainment, the interaction increased slightly $(B=$ $\$ 24,240, \beta=.153, p<.01)$. We did not enter both variables into

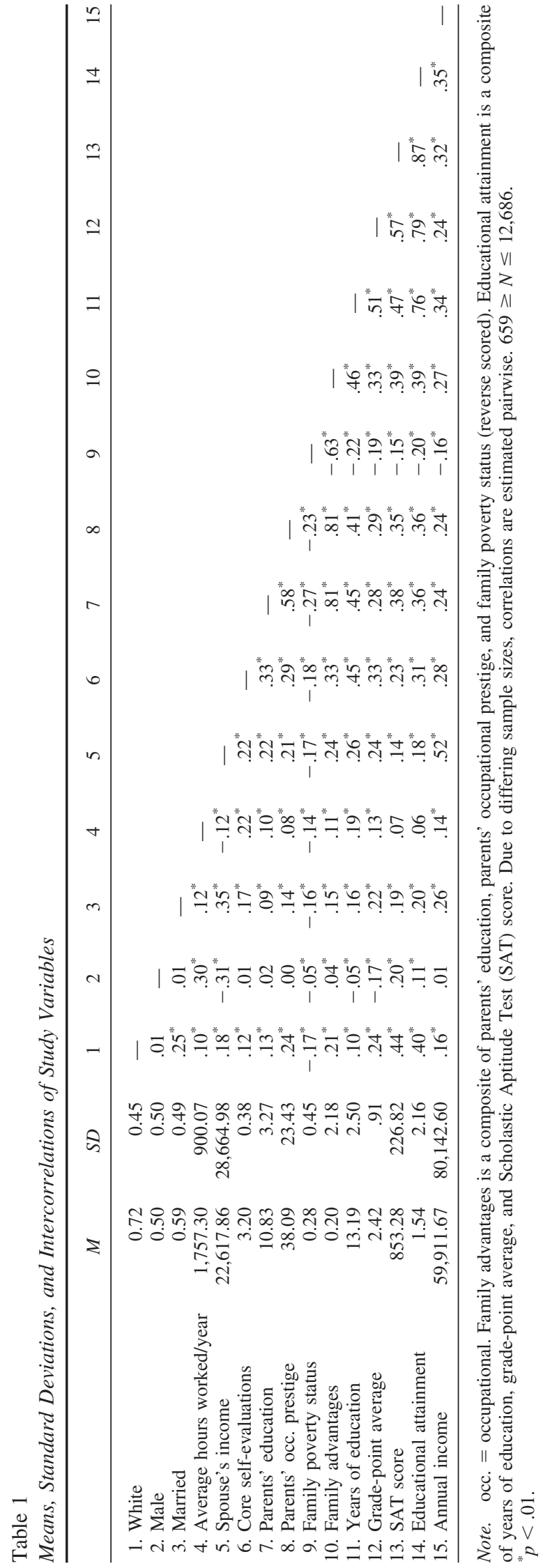


Table 2

Regression Analysis Predicting Income With Family Advantages, Core Self-Evaluations, and Their Interaction

\begin{tabular}{|c|c|c|c|}
\hline Variable & $B$ & $\beta$ & $R^{2}$ \\
\hline Constant & $-\$ 86,956.18$ & - & \\
\hline Step 1: Control variables & & & $.337^{* * *}$ \\
\hline White $(1=$ Caucasian, $0=$ other $)$ & $-\$ 1,199.58$ & -.01 & \\
\hline Male $(1=$ male, $0=$ female $)$ & $\$ 18,790.01^{* * *}$ & $.12^{* *}$ & \\
\hline Married $(1=$ married, $0=$ other $)$ & $\$ 4,879.15^{* *}$ & $.03^{*}$ & \\
\hline Hours worked per year & $\$ 12.04^{* *}$ & $.13^{* *}$ & \\
\hline Spouse's income & $\$ 1.33^{* *}$ & $.51^{* *}$ & \\
\hline Step 2: Main effects & & & $.354^{* *}$ \\
\hline Family advantages & $\$ 4,347.54^{* * *}$ & $.12^{* * *}$ & \\
\hline Core self-evaluations & $\$ 26,295.77^{* * *}$ & $.12^{* *}$ & \\
\hline Step 3: Interaction & & & $.365^{* * *}$ \\
\hline Family Advantages $\times$ Core Self-Evaluations & $\$ 10,504.25^{* *}$ & $.11^{* *}$ & \\
\hline
\end{tabular}

Note. Regression coefficients are given in 2002 dollars. The family advantages variable is a composite of parents' education, parents' occupational prestige, and nonpoverty status. $N=5,525$. For all variables, unstandardized and standardized coefficient estimates are reported from the last step. $\Delta R^{2}=.017$ for Step 2; $\Delta R^{2}=.011$ for Step $3(p \mathrm{~s}<.01)$

${ }^{*} p<.05 .{ }^{* *} p<.01$.

one single analysis so as to maintain the sample size advantages of the analysis of family advantages (see Table 2).

Although the hierarchical regression results suggested that the interaction terms were significant, the amounts of incremental variance explained by the interactions in Tables 2 and 3 were modest (1.1\% and 1.9\%). However, as Ozer (1985) noted, $R^{2}$ is often a misleading measure of effect size, particularly when interpreted in isolation. To further illustrate the form and practical relevance of the interaction, we graphed the interactions involving family advantages and educational attainment in the top and bottom of Figure 1, respectively. The results show that the relationship between family advantages and income is stronger for those with high (1 standard deviation above the mean) CSEs than for those with low (1 standard deviation below the mean) CSEs.
Because the two composite or index variables conceal the practical nature of the variables, we also report the results for the individual family advantages (parents' education and occupational prestige, freedom from poverty) and educational attainment (years of education, high school GPA, SAT scores) separately. These results, from regressions specified in the same manner as those in Tables 2 and 3, are shown in Figures 2, 3, and 4 . The interaction between parents' education and CSEsshown in the top of Figure 2-reveals that the education level of one's parents is much more predictive of income for those high in (1 standard deviation above the mean of) CSE than those low in (1 standard deviation below the mean of) CSE. Put another way, there was a small difference $(\$ 3,989)$ between individuals high and low in CSEs at low parental education

Table 3

Regression Analysis Predicting Income With Educational Attainment, Core Self-Evaluations, and Their Interaction

\begin{tabular}{|c|c|c|c|}
\hline Variable & $B$ & $\beta$ & $R^{2}$ \\
\hline Constant & $-\$ 160,556.77$ & & \\
\hline Step 1: Control variables & & & $.337^{* *}$ \\
\hline White $(1=$ Caucasian, $0=$ other $)$ & $\$ 5,305.15$ & .02 & \\
\hline Male $(1=$ male, $0=$ female $)$ & $\$ 29,605.21^{* * *}$ & $.13^{* *}$ & \\
\hline Married $(1=$ married, $0=$ other $)$ & $\$ 8,327.47$ & .03 & \\
\hline Hours worked per year & $\$ 18.41^{* * *}$ & $.14^{* *}$ & \\
\hline Spouse's income & $\$ 1.47^{* * *}$ & $.56^{* *}$ & \\
\hline Step 2: Main effects & & & $.424^{* *}$ \\
\hline Educational attainment & $\$ 5,702.38^{* * *}$ & $.11^{\text {** }}$ & \\
\hline Core self-evaluations & $\$ 41,499.44^{* * *}$ & $.11^{* *}$ & \\
\hline Step 3: Interaction & & & $.443^{* *}$ \\
\hline Educational Attainment $\times$ Core Self-Evaluations & $\$ 23,002.46^{* * *}$ & $.15^{* *}$ & \\
\hline
\end{tabular}

Note. Regression coefficients are given in 2002 dollars. Educational attainment is a composite of participants' years of education, high school grade point average, and Scholastic Aptitude Test scores. $N=617$. For all variables, unstandardized and standardized coefficient estimates are reported from the last step. $\Delta R^{2}=.087$ for Step $2 ; \Delta R^{2}=.021$ for Step $3(p s<.01)$.

${ }^{* * *} p<.01$ 


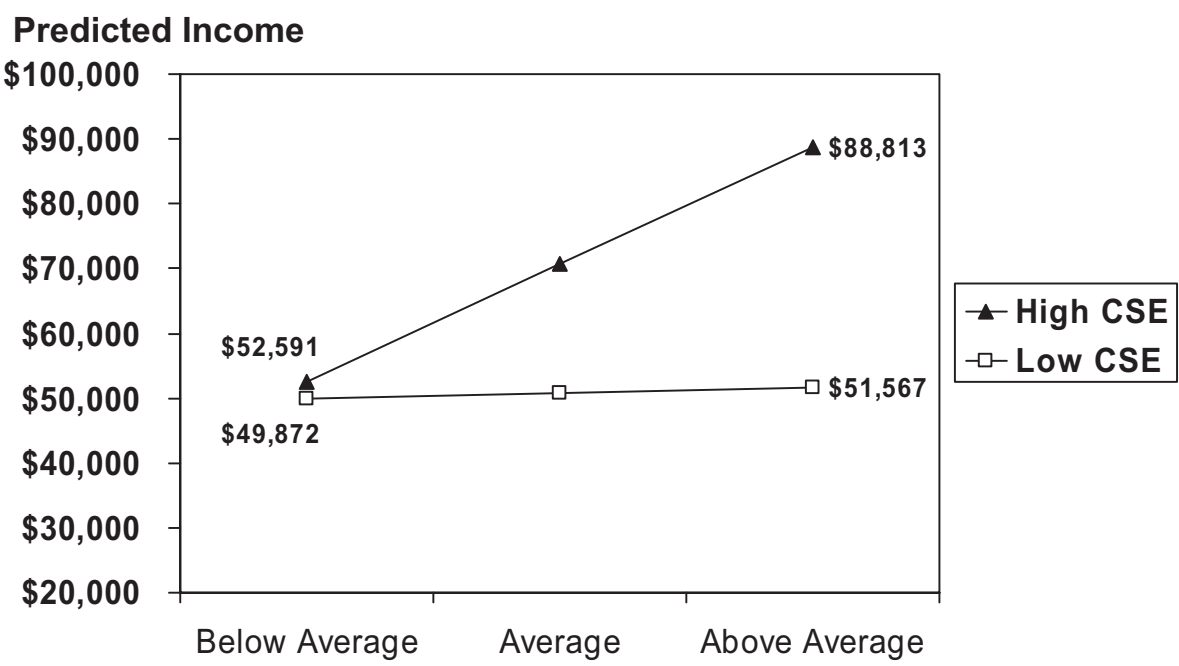

\section{Family Advantages}

\section{Predicted Income}

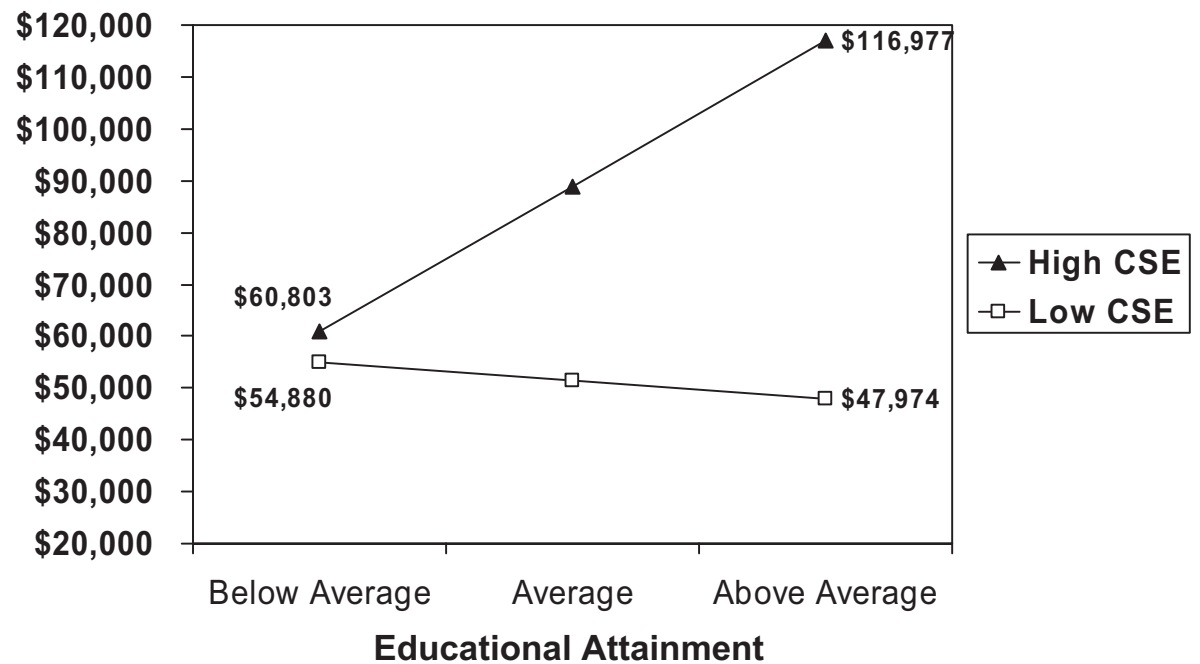

Figure 1. Interaction of core self-evaluations (CSEs) with family advantages (top), and interaction of CSEs with educational attainment (bottom). High CSE $=1$ standard deviation above the mean on core selfevaluations; low CSE $=1$ standard deviation below the mean on core self-evaluations. Above and below average values for family advantages and educational attainment are \pm 1 standard deviation from the mean.

levels but a much larger difference $(\$ 34,001)$ at high levels of parents' education. The bottom of Figure 2 and top of Figure 3 reveal very similar results for the other family advantages variables-parents' occupational prestige and living above versus below the poverty line at the commencement of the study.

Turning to the educational attainment variables, as shown in the bottom of Figure 3, years of education had a mildly positive effect on earnings for those with negative CSEs but a much stronger effect on earnings for those who have positive CSEs. Similarly, as shown in Figure 4, for individuals with negative CSEs, having good high school grades, or high SAT scores, is of little or no benefit. However, for individuals with positive CSEs, these grades and test scores translate into important income advantages.
As another means of analyzing the nature of the interaction, we conducted simple slopes analysis using the approach of Aiken and West (1991) and the software developed by Schubert and Jacoby (http://www.igroup.org/projects/sissy/). For the family advantages composite variable, the slope for individuals 1 standard deviation above the mean on CSEs was $B=\$ 13,187, \beta=.34(p<.01)$. The slope of those 1 standard deviation below the mean was $B=$ $\$ 3,107, \beta=.08(p<.05)$. For the educational attainment composite variable, the slope for individuals 1 standard deviation above the mean of CSE was $B=\$ 11,318, \beta=.23(p<.01)$, whereas the slope for those 1 standard deviation below the mean on CSE was $B=\$ 1,370, \beta=.03(n s)$. These results confirm that family advantages and educational attainment operate more 
Predicted Income

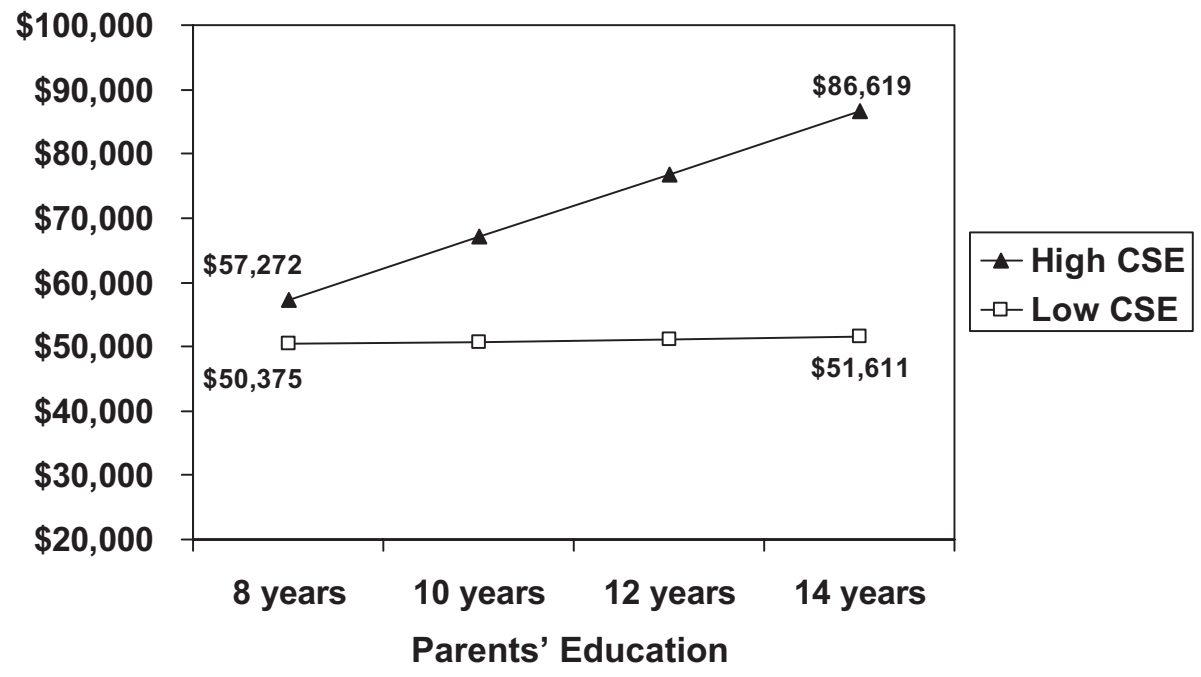

Predicted Income

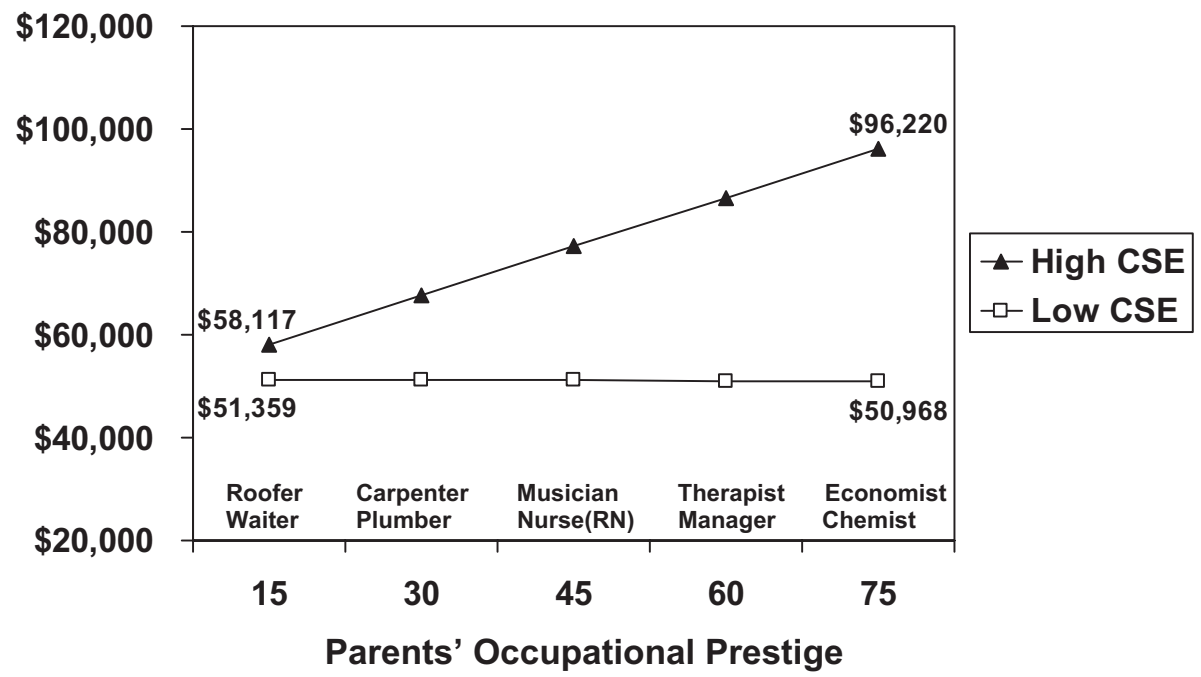

Figure 2. Interaction of core self-evaluations (CSEs) with parents' education (top), and interaction of CSEs with parents' occupational prestige (bottom). High CSE $=1$ standard deviation above the mean on core self-evaluations; low CSE $=1$ standard deviation below the mean on core self-evaluations.

strongly for those with high or positive CSE than for those with low or negative CSE.

Because individuals with positive CSEs might be expected to start their own businesses, we investigated (a) whether CSE was linked to being self-employed, (b) whether self-employment was linked to income, and whether controlling for self-employment affected the coefficients of (c) CSEs or (d) the interactions on income. In estimating these relationships, we computed a variable indicating the average degree to which an individual was selfemployed over the interval for which we assessed income (19942002). The average of this variable was .076 , indicating that the average individual was self-employed $7.6 \%$ of the time from 1994 to 2002 . First, there was a small but significant positive correlation between self-employment and CSE $(r=.04, p<.01)$, indicating a slight tendency for self-employed individuals to score higher on CSEs. Second, self-employment was positively related to income $(r=.14, p<.01)$, indicating that self-employed people earned significantly more. Third, controlling for self-employment status did not affect the coefficient of CSEs on income. For example, in the regressions involving family advantages and educational attainment in Tables 2 and 3, the coefficient on CSEs did not change in the former case and increased slightly in the latter case (from $\beta=.11$ [see Table 3] to $\beta=.12$ after controlling for selfemployment). Fourth, controlling for self-employment did not significantly affect the interaction effects in any analysis. For example, for the interactions involving family advantages and 
Predicted Income

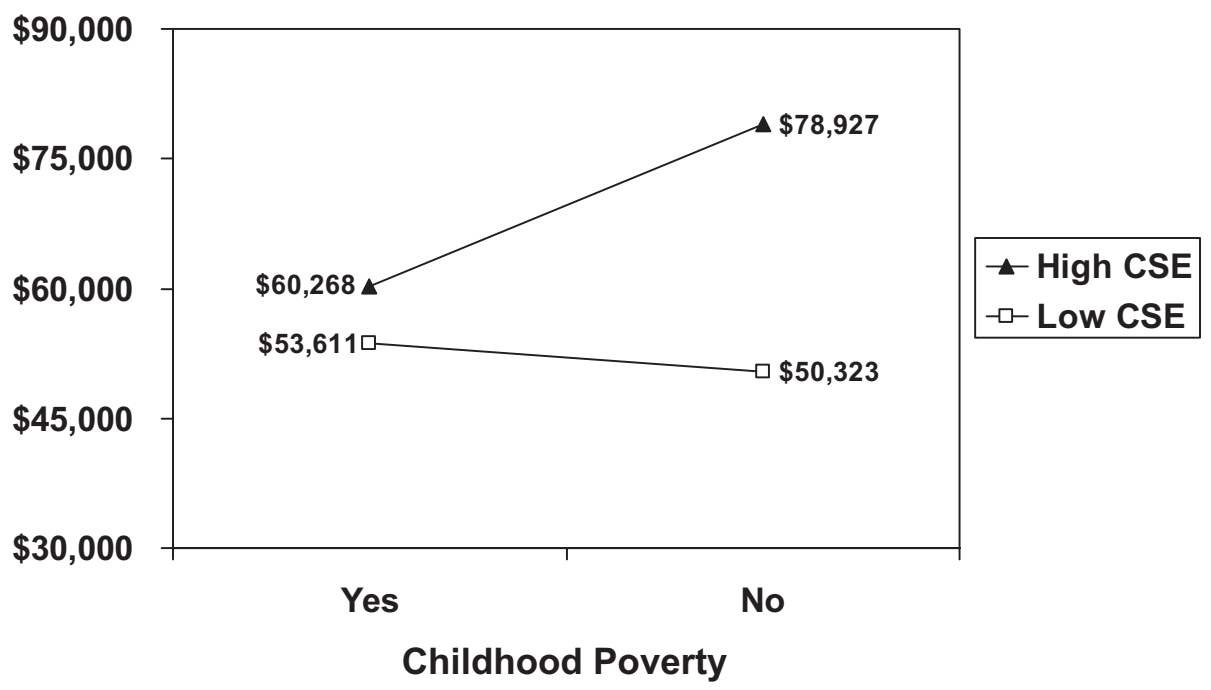

Predicted Income

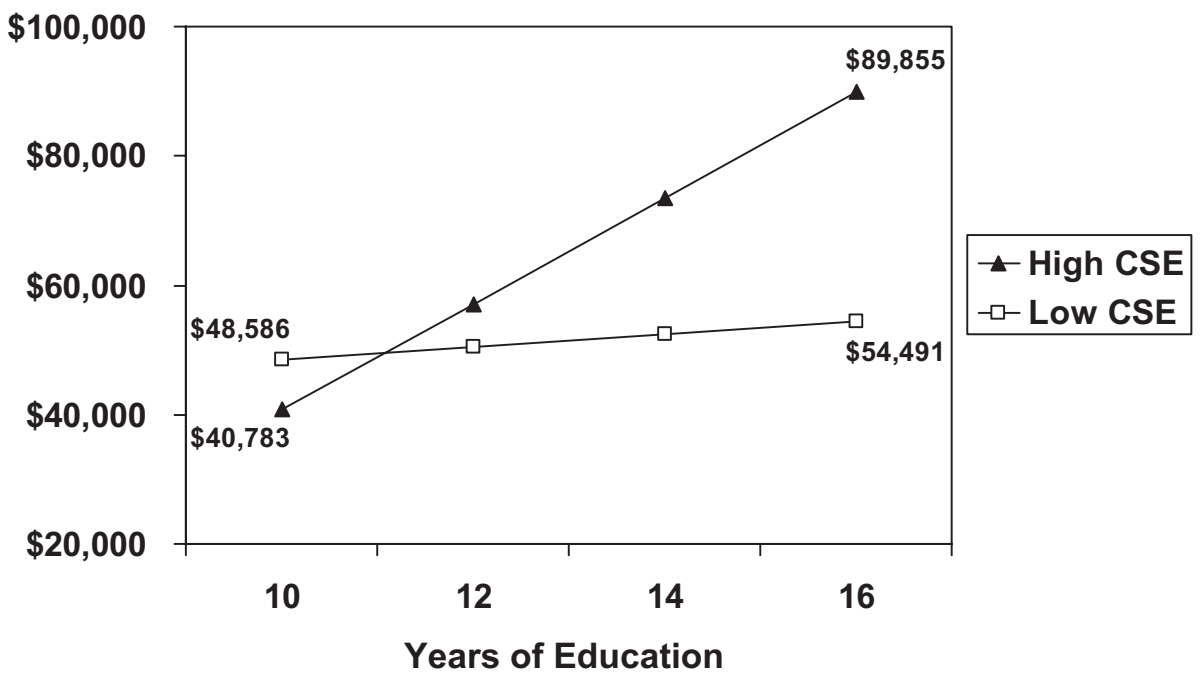

Figure 3. Interaction of core self-evaluations (CSEs) with family poverty status (top), and interaction of CSEs with participants' years of education (bottom). High CSE $=1$ standard deviation above the mean on core self-evaluations; low CSE $=1$ standard deviation below the mean on core self-evaluations.

educational attainment in Tables 2 and 3, the coefficient on the interaction involving family advantages was unchanged from that reported in Table $2(\beta=.11)$, and the interaction involving educational attainment increased slightly, from $\beta=.15$ (see Table 3 ) to $\beta=.16$. Thus, even though individuals with positive CSEs are slightly more likely to be self-employed, and self-employment is correlated with income, controlling for self-employment had little effect on the results.

\section{Discussion}

Our primary purpose in this study was to examine whether people with a positive self-concept capitalize better on those advantages accrued in their youth that tend to be associated with long-term material success. We found that CSEs were a significant moderator of each of the socioeconomic and academic achievement variables examined. Higher socioeconomic status, strong academic performance, and educational attainment in adolescence and young adulthood all had more positive effects on income later in life among those with high CSE compared with those with low CSE. In fact, these resources barely seemed to make a difference for individuals with low CSE and, in some cases (i.e., SAT scores), actually seemed to have a slight negative impact. It seems that resources, such as family advantages, and positive CSE together are necessary to the attainment of above average levels of income. 


\section{Predicted Income}

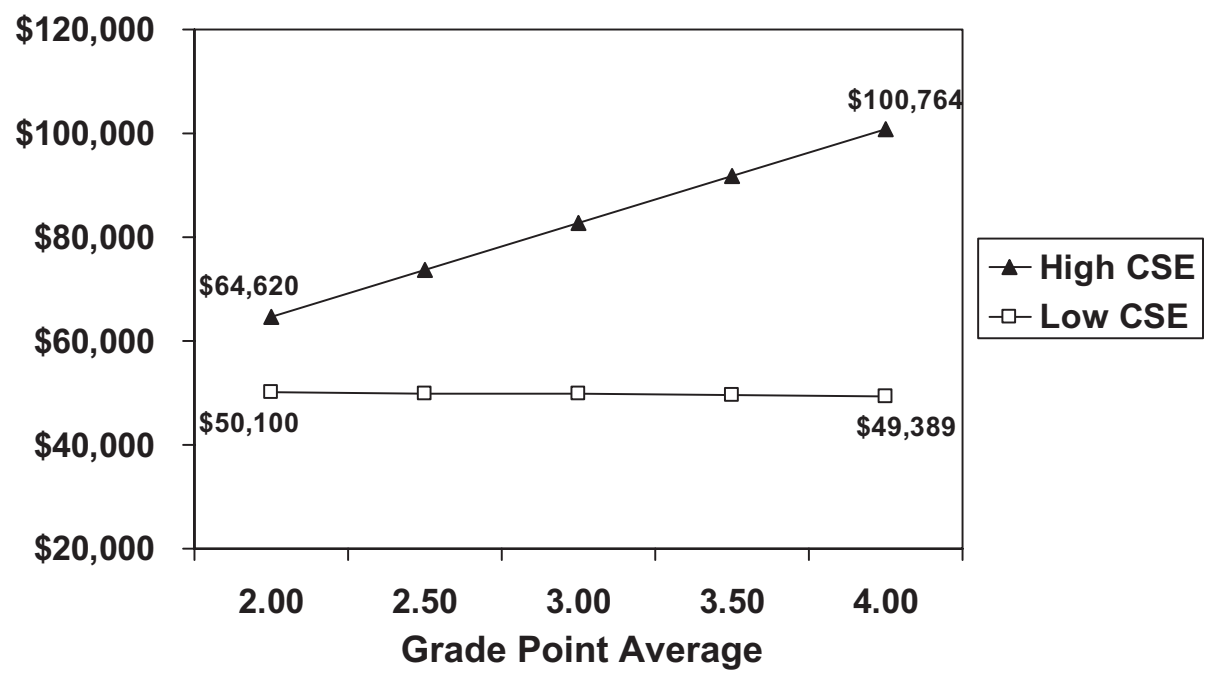

\section{Predicted Income}

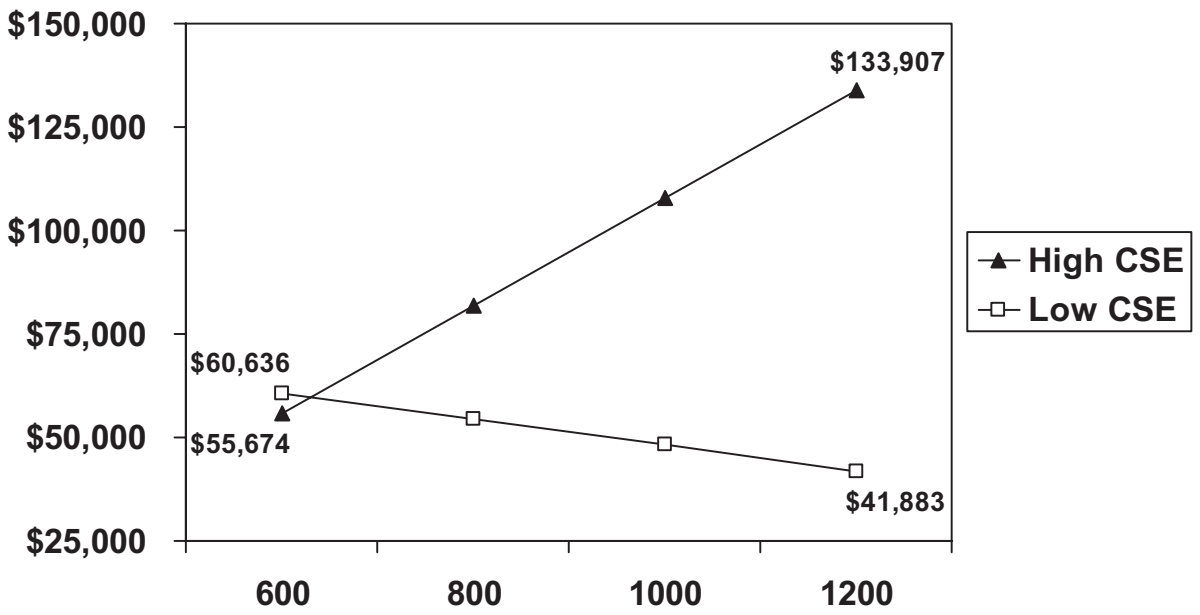

SAT Score

Figure 4. Interaction of core self-evaluations (CSEs) with high-school grade point average (top), and interaction of CSEs with Scholastic Aptitude Test (SAT) scores (bottom). High CSE $=1$ standard deviation above the mean on core self-evaluations; low $\mathrm{CSE}=1$ standard deviation below the mean on core self-evaluations.

Thus, although our results attest to the importance of personality in obtaining objective success, they also support the Lewinian perspective in that the highest level of success is attained by those who have favorable early life circumstances and the "right" temperament to exploit those early advantages.

These findings reveal that, consistent with past research, people can profit from positive events beyond the effects of the events themselves. Furthermore, the time span of this study suggests that the benefits of capitalization are not simply a matter of whether one can continue to feel good about a positive experience the next day or the next week but also of the extent to which one can translate resources into long-term gains. Whether one manages to do so may be explained by one's basic assumptions about oneself.
In fact, CSE seems to explain not only who will benefit from advantages but whether individuals will benefit at all. Harkening back to Seligman and Csikszentmihalyi's (2000) comment, quoted earlier, the results presented in this study confirm that not all individuals flourish under benign circumstances. Some do just as poorly as, or worse than, those exposed to greater adversity, depending on their core self-concept.

It is surprising to see how little positive impact socioeconomic status has in the presence of low CSE in light of popular beliefs that kids from middle- and upper-class families "have it made" and the substantial body of research that seems to support such beliefs. Even more surprising, however, are the interactive effects of CSE with academic achievement when one considers that, in a country 
that prides itself on being merit based and egalitarian, education is supposed to be the ultimate leveler. Academic achievement is probably the most highly touted and widely supported route to wealth. Yet, results of this study reveal that the incomes of similarly credentialed individuals may vary considerably because of differences in self-concept.

A second purpose of this study was to expand the nomological network of CSE. The relationship of CSE with subjective outcomes, such as job and life satisfaction, has been better established by prior research than its relationship with objective outcomes. Furthermore, CSE has rarely been examined as a moderator. In this study, the main and interactive effects of CSE on income were consistently stronger than the main effects of the socioeconomic and academic variables, suggesting that CSE in youth bears a powerful influence on individuals' career paths and subsequent earnings.

\section{Future Research}

It would be interesting to direct further research toward examining how and why young adults with high CSE better capitalize on their resources, resulting in higher income later in their careers. Schroeder et al.'s (2004) finding that people with low self-esteem were actually more likely to leave jobs where they were given raises than were people with high self-esteem may extend to other aspects of career management. On the basis of the self-verification explanation that individuals are motivated to maintain a stable self-concept, low-CSE individuals may avoid other opportunities that could lead to increased income simply because such opportunities are so rattling to their sense of place in the world.

In addition to self-verification motives, approach and avoidance motivation may lead to different career strategies for positive and negative CSE individuals. The fact that the former appear to set more self-concordant goals (Judge et al., 2005) indicates that they are more approach motivated (motivated toward positive outcomes) than are negative CSE individuals. Meanwhile, the Wood et al. (2005) findings that success prompted individuals with low self-esteem to worry about how well they could do in the future indicates that they are given to avoidance motivation, that is, the tendency to pursue goals related to avoiding negative outcomes. At least one other CSE trait-Neuroticism- has been linked to avoidance motivation as well (Elliot \& Thrash, 2002). Thus, it is worth further exploring in future research how CSE is related to approach and avoidance motivation, particularly relative to other relevant traits like extraversion and positive and negative affectivity.

Another interesting question is whether differences in capitalization are evident immediately or over a longer period of time. Given that CSE has been associated with setting more challenging goals (Erez \& Judge, 2001), it could be that people with higher CSE make more ambitious plans right away-for example, aiming for jobs with higher levels of responsibility directly after receiving a graduate degree or seeking to leverage their parents' career networks early in their own careers. On the other hand, differences in capitalization could take longer to manifest. Perhaps individuals with similar circumstances also initially hold similar expectations about what can be accomplished with the resources they possess. After all, social lore about well-off parents and a good education seems ubiquitous enough to produce fairly consistent impressions among people about their potential benefits. But people with poor self-concepts may be more likely to become discouraged over time if those benefits are not borne out exactly as they expected. Thus, it may take a few years of seeking out jobs commensurate with one's credentials or working the parents' contact list—and running into the inevitable roadblocks - before the advantages of a positive self-concept begin to be seen.

To test these rival hypotheses, we separated earnings into early (1994-1996) and later (2000-2002) categories and then repeated the regressions in Tables 2 and 3 with these two income variables. In this analysis, the interaction of CSEs and educational attainment was slightly stronger in predicting later earnings $(\beta=.10, p<.01)$ than earlier earnings $(\beta=.09, p<.01)$. For the family advantages variable, the coefficient for later earnings was exactly the same as for earlier earnings $(\beta=.08, p<.01)$ and significant in both cases. In all cases, the size of these coefficients was smaller than those reported in Tables 2 and 3. This is likely because separating income into earlier and later categories reduces the variability of the measure, thus attenuating its relationship with the independent variables.

It is important to keep in mind that in our study we examined predictors not only of salary but of income from all sources (excluding spousal income). Because high-CSE individuals may realize greater potential for gain from their circumstances and achievements and more strongly believe in their ability to influence outcomes, they may be more likely to pursue incomeproducing opportunities outside of their jobs. Such individuals may engage in more investment or try to apply their skills to other endeavors, resulting in higher levels of overall earnings. Future research should consider this possibility.

\section{Practical Implications}

Only recently have researchers begun to consider hindrances to the psychosocial well-being of relatively advantaged youth (Luthar \& Latendresse, 2005). Luthar and Latendresse found even higher use of cigarettes, alcohol, and drugs and higher rates of anxiety and depression among suburban youth from high-income households compared with inner-city youth. In turn, suburban adolescents displaying these characteristics had poor grades and teacher ratings. Thus, privileged youth may be more at risk than typically believed.

Numerous researchers have argued that the popular focus on improving the self-esteem of youth is fallacious (see Baumeister, Campbell, Krueger, \& Vohs, 2003). Among their criticisms is that effect sizes in relationships between self-esteem and criteria have been small. However, the effects in this study are hardly negligible, and, in fact, they are quite meaningful in terms of real earnings. This being the case, the outlook for income attainment by advantaged youth with negative CSEs may seem rather bleak. After all, their supposed advantages seem to confer no income advantage at all. However, although further inquiry would be needed to address this possibility, it may be that CSE itself can be enhanced through intervention.

Crocker and Park (2004) argued that seeking to enhance selfesteem can have detrimental long-term effects because of the self-centered means used in its pursuit. Yet, Dubois and Flay (2004) presented a model suggesting that the pursuit of high self-esteem can be conducive to positive outcomes when done in a manner adaptive to the norms and demands of one's environment 
and in concert with the promotion of other aspects of mental health. This suggests that it could be worthwhile to pursue research addressing the potential for deliberate and enduring changes in levels of CSE, which underlies not only global self-esteem but also other aspects of the self-concept that Dubois and Flay's model imply are necessary in order for the pursuit of self-worth to be adaptive, such as a sense of mastery and optimism.

Given evidence that CSE is a fairly stable trait (Judge et al., 2000), it may not seem worthwhile to attempt to change it. However, according to the density distributions approach to personality (Fleeson, 2001), traits are manifested in personality states, that is, behaviors that express various levels of the trait. State levels vary such that an individual may deviate substantially from his or her central tendency, depending on the situation. McNiel and Fleeson (2006) provided evidence that extraverted behaviors and neurotic behaviors led to positive and negative affect, respectively, among individuals who were not high in levels of these traits but were, nonetheless, instructed to act as if they were. Thus, if CSE affects income attainment through certain behaviors related to job performance or career management, then interventions that effect behavior change in those areas - that is, changes in state CSEs-could prove fruitful for those interested in better capitalizing on early advantages. Of course, further research would be needed to determine what behaviors are associated with CSEs and whether meaningful changes can be effected in those behaviors. If the underlying self-view remains negative, then significant behavioral change may not be sustainable or even possible, particularly if CSEs permeate a wide range of behaviors that influence income rather than just a few gross behaviors, like goal setting, that may be affected by appropriate intervention.

Finally, although not the primary focus of this article, it is worth noting that among individuals without early advantages, positive CSEs do little to enhance future earnings. Perhaps this is due to their having few advantages to capitalize on. In that case, interventions that attempt to alter CSEs among disadvantaged youth without changing their circumstances, or vice versa, may not have the desired impact on their long-term material success. This is consistent with Swann, Chang-Schneider, and McClarty's (2007) recent argument that "just as it is not enough to change self-views only, so too is it not enough to change people's behaviors and life circumstances only" (p. 91). Swann et al. also argued that circumstances influence self-views, which could be responsible for the moderate correlation between CSEs and family advantages in our sample $(r=.33)$. If so, this would be further reason to emphasize situational interventions in addition to self-concept change in programs targeting disadvantaged youth.

\section{Conclusion}

Academics have spent considerable time puzzling over why wealth does not translate into happiness (see Csikszentmihalyi, 2000), but they are only beginning to consider that commonly recognized protective factors like material resources, good schooling, and academic achievement far from guarantee even objective success. In this study we have shown that people endowed with these advantages do not necessarily capitalize on them in the long run. Those who do, however, seem best positioned to reap society's rewards, at least in the material sense, and people with positive CSEs are the most likely to capitalize on early advantages.

\section{References}

Aiken, L. S., \& West, S. G. (1991). Multiple regression: Testing and interpreting interactions. Newbury Park, CA: Sage.

Allen, W. R. (1992). The color of success: African-American college student outcomes at predominantly White and historically Black public colleges and universities. Harvard Educational Review, 62, 26-44.

Baumeister, R. F., Campbell, J. D., Krueger, J. I., \& Vohs, K. D. (2003). Does high self-esteem cause better performance, interpersonal success, happiness, or healthier lifestyles? Psychological Science in the Public Interest, 4, 1-44.

Birndorf, S., Ryan, S., Auinger, P., \& Aten, M. (2005). High self-esteem among adolescents: Longitudinal trends, sex differences, and protective factors. Journal of Adolescent Health, 37, 194-201.

Bono, J. E., \& Colbert, A. E. (2005). Understanding responses to multisource feedback: The role of core self-evaluations. Personnel Psychology, 58, 171-203.

Brown, J. D., \& McGill, K. L. (1989). The cost of good fortune: When positive life events produce negative health consequences. Journal of Personality and Social Psychology, 57, 1103-1110.

Bryant, F. B. (2003). Savoring Beliefs Inventory (SBI): A scale for measuring beliefs about savouring. Journal of Mental Health, 12, 175-196.

Busemeyer, J. R., \& Jones, L. E. (1983). Analysis of multiplicative combination rules when the causal variables are measured with error. Psychological Bulletin, 93, 549-562.

Casey, M. B., Nuttall, R., \& Pezaris, E. (1995). The influence of spatial ability on gender differences in mathematics college entrance test scores across diverse samples. Developmental Psychology, 31, 697-705.

Charles, K. K., \& Luoh, M. (2003). Gender differences in completed schooling. Review of Economics \& Statistics, 85, 559-577.

Chênevert, D., \& Tremblay, M. (2002). Managerial career success in Canadian organizations: Is gender a determinant? International Journal of Human Resource Management, 13, 920-941.

Crocker, J., \& Park, L. E. (2004). The costly pursuit of self-esteem. Psychological Bulletin, 130, 392-414.

Csikszentmihalyi, M. (2000). Happiness, flow, and economic equality. American Psychologist, 55, 1163-1164.

Cullen, M. J., Hardison, C. M., \& Sackett, P. R. (2004). Using SAT-grade and ability-job performance relationships to test predictions derived from stereotype threat theory. Journal of Applied Psychology, 89, 220230.

Cunningham, W. A., Preacher, K. J., \& Banaji, M. R. (2001). Implicit attitude measures: Consistency, reliability, and convergent validity. Psychological Science, 12, 163-170.

Diener, E., Nickerson, C., Lucas, R. E., \& Sandvik, E. (2002). Dispositional affect and job outcomes. Social Indicators Research, 59, 229259.

Dreher, G. F., \& Bretz, R. D. (1991). Cognitive ability and career attainment: Moderating effects of early career success. Journal of Applied Psychology, 76, 392-397.

Dubois, D. L., \& Flay, B. R. (2004). The healthy pursuit of self-esteem: Comment on and alternative to the Crocker and Park (2004) formulation. Psychological Bulletin, 130, 415-420.

Duncan, G. J., Yeung, W. J., Brooks-Gunn, J., \& Smith, J. R. (1998). How much does childhood poverty affect the life chances of children? American Sociological Review, 63, 406-423.

Duncan, O. D. (1961). A socioeconomic index for all occupations. In A. J. Reiss, Jr., O. D. Duncan, P. K. Hatt, \& C. C. North (Eds.), Occupations and social status (pp. 109-138). New York: Free Press.

Ek, E., Sovio, U., Remes, J., \& Jarvelin, M. (2005). Social predictors of unsuccessful entrance into the labour market-A socialization process perspective. Journal of Vocational Behavior, 66, 471-486.

Elliot, A. J., \& Thrash, T. M. (2002). Approach-avoidance motivation in personality: Approach and avoidance temperaments and goals. Journal of Personality and Social Psychology, 82, 804-818. 
Erez, A., \& Judge, T. A. (2001). Relationship of core self-evaluations to goal setting, motivation, and performance. Journal of Applied Psychology, 86, 1270-1279.

Finkelstein, S., \& Boyd, B. K. (1998). How much does the CEO matter? The role of managerial discretion in the setting of CEO compensation. Academy of Management Journal, 41, 179-199.

Fleeson, W. (2001). Toward a structure- and process-integrated view of personality: Traits as density distributions of states. Journal of Personality and Social Psychology, 80, 1011-1027.

Fredrickson, B. L., Tugade, M. M., Waugh, C. E., \& Larkin, G. R. (2003). What good are positive emotions in crises? A prospective study of resilience and emotions following the terrorist attacks on the United States on September 11th, 2001. Journal of Personality and Social Psychology, 84, 365-376.

Gable, S. L., Impett, E. A., Reis, H. T., \& Asher, E. R. (2004). What do you do when things go right? The intrapersonal and interpersonal benefits of sharing positive events. Journal of Personality and Social Psychology, 87, 228-245.

Gosling, S. D., Renfrow, P. J., \& Swann, W. B. (2003). A very brief measure of the Big 5 personality domains. Journal of Research in Personality, 37, 504-528.

Grissomand, R. J., \& Kim, J. J. (2005). Effect sizes for research: A broad practical approach. Mahwah, NJ: Erlbaum.

Gullikson, A. (2006). Interpreting OLS regression and transformations. Retrieved March 21, 2006, from Columbia University Web site: http:// www.columbia.edu/ ag2319/teaching/V3212_Outline/node8.html

Hartung, P. J., Porfeli, E. J., \& Vondracek, F. W. (2005). Child vocational development: A review and reconsideration. Journal of Vocational Behavior, 66, 385-419.

Haveman, R., \& Wolfe, B. (1995). The determinants of children's attainments: A review of methods and findings. Journal of Economic Literature, 33, 1829-1878.

Headey, B., \& Wearing, A. (1989). Personality, life events, and subjective well-being: Toward a dynamic equilibrium model. Journal of Personality and Social Psychology, 57, 731-739.

Heller, D., Judge, T. A., \& Watson, D. (2002). The confounding role of personality and trait affectivity in the relationship between job and life satisfaction. Journal of Organizational Behavior, 23, 815835.

Hicklin, J., \& Widiger, T. A. (2000). Convergent validity of alternative MMPI-2 personality disorder scales. Journal of Personality Assessment, 75, 502-518.

John, O. P. \& Srivastava, S. (1999). The Big Five trait taxonomy: History, measurement, and theoretical perspectives. In L. A. Pervin \& O. P. Oliver (Eds.), Handbook of personality: Theory and research (2nd ed.; pp. 102-138). New York: Guilford Press.

Judge, T. A., \& Bono, J. E. (2001). Relationship of core self-evaluations traits-self-esteem, generalized self-efficacy, locus of control, and emotional stability - with job satisfaction and job performance: A metaanalysis. Journal of Applied Psychology, 86, 80-92.

Judge, T. A., Bono, J. E., Erez, A., \& Locke, E. A. (2005). Core selfevaluations and job and life satisfaction: The role of self-concordance and goal attainment. Journal of Applied Psychology, 90, 257-268.

Judge, T. A., Bono, J. E., \& Locke, E. A. (2000). Personality and job satisfaction: The mediating role of job characteristics. Journal of Applied Psychology, 85, 237-249.

Judge, T. A., Erez, A., \& Bono, J. E. (1998). The power of being positive: The relation between positive self-concept and job performance. Human Performance, 11, 167-188.

Judge, T. A., Erez, A., Bono, J. E., \& Thoresen, C. J. (2003). The Core Self-Evaluations Scale (CSES): Development of a measure. Personnel Psychology, 56, 303-331.

Judge, T. A., Erez, A., Thoresen, C. J., \& Bono, J. E. (2002). Are measures of self-esteem, neuroticism, locus of control, and generalized self- efficacy indicators of a common core construct? Journal of Personality and Social Psychology, 83, 693-710.

Judge, T. A., Locke, E. A., \& Durham, C. C. (1997). The dispositional causes of job satisfaction: A core evaluations approach. Research in Organizational Behavior, 19, 151-188.

Judge, T. A., Locke, E. A., Durham, C. C., \& Kluger, A. N. (1998). Dispositional effects on job and life satisfaction: The role of core evaluations. Journal of Applied Psychology, 83, 17-34.

Kline, R. B. (2004). Beyond significance testing: Reforming data analysis methods in behavioral research. Washington, DC: American Psychological Association.

Langston, C. A. (1994). Capitalizing on and coping with daily-life events: Expressive responses to positive events. Journal of Personality and Social Psychology, 67, 1112-1125.

Lee, K., Ashton, M. C., \& de Vries, R. E. (2005). Predicting workplace delinquency and integrity with the HEXACO and five-factor models of personality structure. Human Performance, 18, 179-197.

Luthar, S. S., \& Latendresse, S. J. (2005). Children of the affluent: Challenges to well-being. Current Directions in Psychological Science, $14,49-53$.

Lyubomirsky, S., King, L., \& Diener, E. (2005). The benefits of frequent positive affect: Does happiness lead to success? Psychological Bulletin, $131,803-855$.

MacKenzie, S. B., Podsakoff, P. M., \& Jarvis, C. B. (2005). The problem of measurement model misspecification in behavioral and organizational research and some recommended solutions. Journal of Applied Psychology, 90, 710-730.

MacLeod, A. K., \& Conway, C. (2005). Well-being and the anticipation of future positive experiences: The role of income, social networks, and planning ability. Cognition \& Emotion, 19, 357-374.

Magnus, K., Diener, E., Fujita, F., \& Payot, W. (1993). Extraversion and neuroticism as predictors of objective life events: A longitudinal analysis. Journal of Personality and Social Psychology, 65, 10461053.

Margit, W., Vondracek, F. W., Capaldi, D. M., \& Porfeli, E. (2003). Childhood and adolescent predictors of early adult career pathways Journal of Vocational Behavior, 63, 305-328.

McCullough, M. E., Tsang, J., \& Emmons, R. A. (2004). Gratitude in intermediate affective terrain: Links of grateful moods to individual differences and daily emotional experience. Journal of Personality and Social Psychology, 86, 295-309.

McNiel, J. M., \& Fleeson, W. (2006). The causal effect of extraversion on positive affect and neuroticism on negative affect: Manipulating state extraversion and state neuroticism in an experimental approach. Journal of Research in Personality, 40, 529-550.

Mullen, A. L., Goyette, K. A., \& Soares, J. A. (2003). Who goes to graduate school? Social and academic correlates of educational continuation after college. Sociology of Education, 76, 143-169.

Ng, T. W. H., Eby, L. T., Sorensen, K. L., \& Feldman, D. C. (2005). Predictors of objective and subjective career success: A meta-analysis. Personnel Psychology, 58, 367-408.

O'Reilly, C. A., \& Chatman, J. A. (1994). Working smarter and harder: A longitudinal study of managerial success. Administrative Science Quarterly, 39, 603-627.

Ozer, D. J. (1985). Correlation and the coefficient of determination. Psychological Bulletin, 97, 307-315.

Pearlin, L. I., Lieberman, M. A., Menaghan, E. G., \& Mullan, J. T. (1981). The stress process. Journal of Health and Social Behavior, 22, 337-353.

Pfeffer, J. (1977). Effects of an MBA and socioeconomic origins on business school graduates' salaries. Journal of Applied Psychology, 62, 698-705.

Radloff, L. (1997). The CES-D scale: A self-report depression scale for research in the general population. Applied Psychological Measurement, $1,385-401$. 
Roberts, B. W., Caspi, A., \& Moffitt, T. E. (2003). Work experiences and personality development in young adulthood. Journal of Personality and Social Psychology, 84, 582-593.

Rosenberg, M. (1989). Society and the adolescent self-image (Rev. ed.). Middletown, CT: Wesleyan University Press.

Ross, C. E., \& Mirowsky, J. (1989). Explaining the social patterns of depression: Control and problem solving-or support and talking? Journal of Health and Social Behavior, 30, 206-209.

Rotter, J. B. (1966). Generalized expectancies for internal versus external control of reinforcement. Psychological Monographs General and Applied, 80 (1, Whole No. 609).

Rumberger, R., \& Daymont, T. N. (1982). The effects of high school curriculum on labor market success. In M. E. Borus (Ed.), Pathways to the future: Vol. 2. A final report on the National Longitudinal Survey of Youth labor market experience in 1980. Columbus: Ohio State University, Center for Human Resource Research.

Russell, C. J., \& Dean, M. A. (2000). To log or not to log: Bootstrap as an alternative to the parametric estimation of moderation effects in the presence of skewed dependent variables. Organizational Research Methods, 3, 166-185.

Schroeder, D., Josephs, R., \& Swann, W. B., Jr. (2004). Foregoing lucrative employment to preserve low self-esteem. Unpublished manuscript, University of Texas.

Seligman, M. E. P., \& Csikszentmihalyi, M. (2000). Positive psychology. American Psychologist, 55, 5-15.

Smart, J. C., \& Pascarella, E. T. (1986). Socioeconomic achievements of former college students. Journal of Higher Education, 57, 529-549.

Staw, B. M., Sutton, R. I., \& Pelled, L. H. (1994). Employee positive emotion and favorable outcomes at the workplace. Organization Science, 5, 51-71.

Stober, J. (2001). The social desirability scale-17 (SDS-17): Convergent validity, discriminant validity, and relationship with age. European Journal of Psychological Assessment, 17, 222-232.

Swann, Jr., W. B. (2005). The self and identity negotiation. Interaction Studies, 6, 69-83.

Swann, Jr., W. B., Chang-Schneider, C., \& McClarty, K. L. (2007). Do people's self-views matter? Self-concept and self-esteem in everyday life. American Psychologist, 62, 84-94.

Tsui, L. (1998). The effects of gender, education, and personal skills self-confidence on income in business management. Sex Roles, 38, 363-373.

Tugade, M. M., \& Fredrickson, B. L. (2004). Resilient individuals use positive emotions to bounce back from negative emotional experiences. Journal of Personality and Social Psychology, 86, 320-333.

U.S. Census Bureau. (1971). 1970 Census of Population alphabetical index of industries and occupations. Washington, DC: U.S. Government Printing Office.

U.S. Office of Economic Opportunity/Community Services Administration. (1978). The 1978 poverty guidelines: One version of the [U.S.] federal poverty measure. Washington, DC: U.S. Census Bureau.

Wanberg, C., Glomb, T. M., Song, Z., \& Sorenson, S. (2005). Job search persistence during unemployment: A 10-wave longitudinal study. Journal of Applied Psychology, 3, 411-430.

Warren, J. R., \& Hauser, R. M. (1997). Social stratification across three generations: New evidence from the Wisconsin Longitudinal Study. American Sociological Review, 62, 561-572.

Wood, J. V., Heimpel, S. A., Newby-Clark, I. R., \& Ross, M. (2005) Snatching defeat from the jaws of victory: Self-esteem differences in the experience and anticipation of success. Journal of Personality and Social Psychology, 89, 764-780.

Woods, S. A., \& Hampson, S. E. (2005). Measuring the Big 5 with single items using a bipolar response scale. European Journal of Personality, $19,373-390$. 
Appendix

Measure of Core Self-Evaluations

1. I have little control over the things that happen to me. (reverse scored)

2. There is little I can do to change many of the important things in my life. (reverse scored)

3. What happens to me in the future mostly depends on me.

4. I feel that I am a person of worth, on an equal basis with others.

5. I feel that I have a number of good qualities.

6. All in all, I am inclined to feel that I am a failure. (reverse scored)

7. I feel I do not have much to be proud of. (reverse scored)

8. I wish I could have more respect for myself. (reverse scored)

9. I've been depressed. (reverse scored)

10. I've felt hopeful about the future.

11. What happens to me is of my own doing.

12. When I make plans, I am almost certain to make them work.

Note. Three items (Items 1, 2, and 3) were taken from "The Stress Process," by L. I. Pearlin, M. A. Lieberman, E. G. Menaghan, and J. T. Mullan, 1981, Journal of Health and Social Behavior, 22, p. 353. Copyright 1981 by L. I. Pearlin. Pearlin's personal mastery measure assesses the degree to which individuals perceive themselves in control of forces that impact their lives. Five items (Items 4, 5, 6, 7, and 8) were taken from Society and the Adolescent Self-image (Rev. ed.), by M. Rosenberg, 1989, Middletown, CT: Wesleyan University Press. Copyright 1989 by M. Rosenberg. Two items (Items 9 and 10) were taken from the Center for Epidemiological Studies Depression scale (see Radloff, 1997; Ross \& Mirowsky, 1989). Two items (Items 11 and 12) were taken from the internal-external locus of control measure in "Generalized Expectancies for Internal Versus External Control of Reinforcement," by J. B. Rotter, 1966. Psychological Monographs General and Applied, 80 (1, Whole No. 609). Copyright 1966 by J. B. Rotter.

Received August 20, 2006

Revision received January 11, 2007

Accepted February 2, 2007 